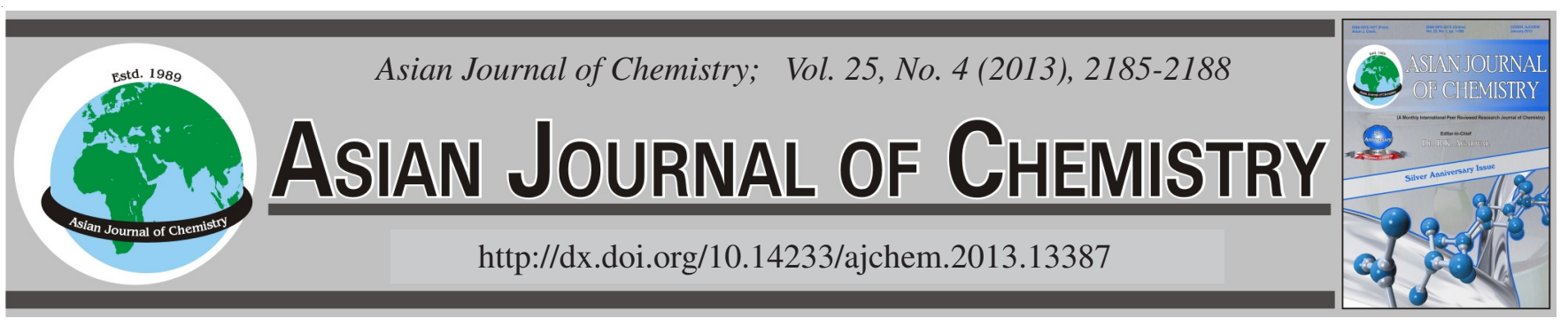

\title{
UV-VIS, Fluorescence and Mass Spectrometry Investigation on the Transition Metal Ion Chelation of Two Bioisosteres of Resveratrol
}

\author{
Wen Qin ${ }^{1,2}$, Biqun Zou ${ }^{1}$, Ye Zhang ${ }^{1,2, *}$ XiAnghui YI $^{1,2}$ and Zhenghong Pan ${ }^{2, *}$ \\ ${ }^{1}$ Department of Chemistry, Guilin Normal College, Guangxi 541001, P.R. China \\ ${ }^{2}$ Guangxi Key Laboratory of Functional Phytochemicals Research and Utilization, Guangxi Institute of Botany, Guilin 541006, P.R. China \\ *Corresponding author: Fax: +86 77 32806321; Tel: +86 77 32823285; E-mail: zhangye_81@yahoo.com.cn; pan9418@yahoo.com.cn

\begin{abstract}
2-[(o-Hydroxylphenylimino)methyl]phenol (OSAP) and 2-((p-hydroxylphenylimino)methyl)phenol (PSAP), two bioisosteres of the natural antioxidant resveratrol, are biologically interesting antioxidants. In order to probe whether they exert their antioxidant effect through metal ions chelation, the $\mathrm{Cu}$ (II) ion and $\mathrm{Fe}(\mathrm{II})$ ion chelating abilities of these compounds were measured by UV-VIS, fluorescence and mass spectroscopy, respectively. From UV-VIS spectra, the binding constants of OSAP with $\mathrm{Cu}^{2+}$ and $\mathrm{Fe}^{2+}$ were determined to be $7.58 \times$ $10^{3}$ and $2.22 \times 10^{3} \mathrm{M}^{-1}$ by Benesi-Hildebrand method, while that of PSAP were found to be $6.20 \times 10^{3}$ and $2.08 \times 10^{4} \mathrm{M}^{-1}$, respectively. From fluorescence quenching spectra, the Stern-Volmer quenching constants of OSAP with $\mathrm{Cu}^{2+}$ and $\mathrm{Fe}^{2+}$ were assessed to be $6.06 \times 10^{4}$ and $6.70 \times 10^{4} \mathrm{M}^{-1}$, respectively, while that of PSAP were calculated to be $8.45 \times 10^{4}$ and $1.43 \times 10^{5} \mathrm{M}^{-1}$. In addition, mass spectrometry studies showed that both OSAP and PSAP formed a 2:1 complex with ferrous when they were treated with $\mathrm{Fe}^{2+}$ in a 8:2 (v:v) methanolwater solution, respectively. The above results demonstrated the relatively significant role of the transition metal ion chelation in their antioxidant abilities.
\end{abstract}

Key Words: Transition metal ion chelation, Binding constant, Stern-Volmer quenching constant, Complexation, Antioxidant activity.

\section{INTRODUCTION}

Hydroxyl radical and lipid peroxidation, catalyzed by transition metal ions through Haber-Weiss and Fenton reaction in the course of the organisms' metabolic actions, would cause oxidative damage to lipids, proteins and DNA, that could lead to some degenerative diseases of aging and age-related diseases, such as cancer, Alzheimer's disease and Parkinson disease ${ }^{1,2}$. Chelation of transition metal ions could be important to prevent or minimize these damages ${ }^{3,4}$. The antioxidants chelating agents with transition metal ions (especially copper ion and ferrous ion) to get stable complex and stabilize transition metal ions in low oxidation state could prevent the generation of hydroxyl radical, reactive oxygen species and oxidative damage $^{3,4}$. This is the so-called transition metal ions chelation mechanism, which is one of the functional mechanisms of antioxidant $\mathrm{t}^{3-5}$.

2-[(o-Hydroxylphenylimino)methyl]phenol (OSAP) and 2-[(p-hydroxylphenylimino)methyl]phenol (PSAP), two bioisosteres of the natural antioxidant resveratrol ${ }^{6,7}$, are biologically interesting antioxidants and have showed excellent antioxidant activity ${ }^{8,9}$. It is well known that resveratrol is a famous and non-toxic natural antioxidant, so its bioisosteres
OSAP and PSAP have good potential to be new outstanding antioxidants ${ }^{8,9}$. It would thus be interesting to explore if, transition metal ion chelation play an important role in the antioxidant properties of OSAP and PSAP. In addition, a look at the structures of OSAP and PSAP that they contain "metal ion-binding motifs" and are thus expected to effectively bind transition metal ions. So UV-VIS and fluorescenece spectroscopy, as well as mass spectra, were employed to study their transition metal ions chelating abilities through the respective chelation of copper and ferrous ions.

\section{EXPERIMENTAL}

OSAP and PSAP were synthesized according to the literature $^{8}$. All chemicals and solvents used were of analytical grade. Methanol was distilled prior to use. The TU-1901 UVVIS spectrophotometer was used to evaluate the binding constants. The fluorescence spectroscopy was scanned by the RF-5301 spectrophotometer. The mass spectral studies were done using BRUKER ESQUIRE HCT instrument.

Interactions between OSAP/PSAP with $\mathrm{Cu}^{2+} / \mathrm{Fe}^{2+}$ assessed by UV-visible and fluorescence spectrophotometer: The chelation abilities with $\mathrm{Cu}^{2+}$ and $\mathrm{Fe}^{2+}$ were firstly investigated 
by UV-visible and fluorescence-quenching spectroscopy. Both concentrations of OSAP and PSAP were dissolved to the concentration $1.0 \times 10^{-3} \mathrm{M}$ in DMF-water solution ( $\mathrm{v}: \mathrm{v}=7: 3$, $\mathrm{pH}=6.80 \pm 0.15)$. Ferrous nitrate and copper nitrate were dissolved to the proper concentration (in serial concentration) in the same solution, respectively. After respective addition of $25 \mu \mathrm{L}$ ferrous nitrate or copper nitrate solution into $500 \mu \mathrm{L}$ OSAP (and PSAP) solution, the mixtures were settled to the volume of $1 \mathrm{~mL}$ and allowed to stand for $0.5 \mathrm{~h}$ (until the stable) with intermittent shaking and the UV-VIS and fluorescence spectra was scanned, respectively.

Interactions between OSAP/PSAP with $\mathrm{Cu}^{2+} / \mathrm{Fe}^{2+}$ assessed by mass spectrometer $10 \mu \mathrm{M}$ ferrous sulphate were respectively treated with $30 \mu \mathrm{M}$ OSAP and PSAP in a 8:2 (v:v) methanolwater solution and the mixtures were allowed to stand for 0.5 $\mathrm{h}$ and then were evaluated by the BRUKER ESQUIRE HCT instrument, respectively.

\section{RESULTS AND DISCUSSION}

UV-visible spectra studies on the interactions between OSAP/PSAP and $\mathrm{Cu}^{2+} / \mathrm{Fe}^{2+}$ : OSAP were titrated with increasing amounts of $\mathrm{Cu}^{2+}$ and $\mathrm{Fe}^{2+}$ in DMF- $\mathrm{H}_{2} \mathrm{O}$ solution, respectively. The titration was monitored by UV/visible spectra (Fig. 1). Two absorbance bands were observed at 270 and $353 \mathrm{~nm}$ for the OSAP and were generally ascribed to $\pi-\pi^{*}$ electronic transitions from the conjugated benzene-Schiff base-benzene system. In Fig. 1(A), as $\mathrm{Cu}^{2+}$ was added, the OSAP absorbance peaks centered at 270 and $352 \mathrm{~nm}$ decreased in intensity while the absorbance in the regions between 400 and $500 \mathrm{~nm}$ increased in intensity, implying clean formation of the OSAP$\mathrm{Cu}^{2+}$ complex. In Fig. 1(B), as $\mathrm{Fe}^{2+}$ was added, the similar phenomenon was also happened as that in the in Fig. 1(A), suggesting clear formation of the OSAP-Fe ${ }^{2+}$ complex. The results showed good transition metal ion chelation of OSAP.

A similar respective titration of PSAP with $\mathrm{Cu}^{2+}$ and $\mathrm{Fe}^{2+}$ was carried out in the same condition. The spectra for these titrations were shown in Fig. 2. Two absorbance bands were observed at 272 and $352 \mathrm{~nm}$ for the PSAP and were also ascribed to $\pi-\pi *$ electronic transitions from the conjugated benzene-Schiff base-benzene system. In Fig. 2(A), as $\mathrm{Cu}^{2+}$ was added, the PSAP absorbance peak centered at $352 \mathrm{~nm}$ decreased in intensity while the absorbance peak centered at $272 \mathrm{~nm}$ and the absorbance in the regions between 400 and $450 \mathrm{~nm}$ increased in intensity, suggesting the firm formation of the PSAP-Cu${ }^{2+}$ complex. In Fig. 2(B), as $\mathrm{Fe}^{2+}$ was added, the PSAP absorbance peaks centered at 272 and $352 \mathrm{~nm}$ decreased in intensity, indicating effective formation of the PSAP-Fe ${ }^{2+}$ complex. The results demonstrated that the transition metal ion chelation effectively made when PSAP treated with transition metal ions $\left(\mathrm{Cu}^{2+} / \mathrm{Fe}^{2+}\right)$.

The binding constants $\left(\mathrm{K}_{\mathrm{a}}\right)$ were determined from their UV/visible spectral data using Benesi-Hildebrand plots, involving plots of the inverse of metal ion $\left(\mathrm{Cu}^{2+}\right.$ and $\left.\mathrm{Fe}^{2+}\right)$ concentrations against the inverse of changes in their respective absorbances $\left(1 / \Delta \mathrm{A}\right.$ versus $\left.1 /\left[\mathrm{M}^{2+}\right]\right)$ as that in Fig. $3^{10}$. Eqn. 1 was used to calculate the binding constants from these plots:

$$
\frac{1}{\Delta \mathrm{A}}=\frac{1}{\mathrm{~K}_{\mathrm{a}} \Delta \mathrm{A}\left[\mathrm{M}^{2+}\right]}+\frac{1}{\Delta \mathrm{A}}
$$
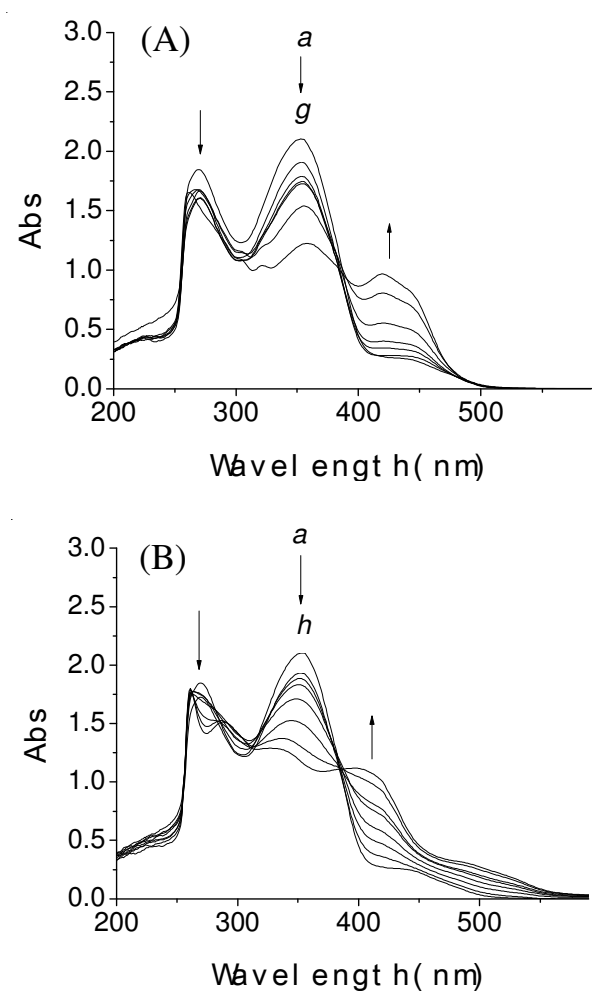

Fig. 1. UV-visible spectrophotometric titration of OSAP with (A) $\mathrm{Cu}^{2+}(\mathrm{B})$ $\mathrm{Fe}^{2+}$. The concentrations of $\mathrm{Cu}^{2+}\left(\mathrm{Fe}^{2+}\right)$ a $\rightarrow \mathrm{g}(\mathrm{a} \rightarrow \mathrm{h})$ were: $0,2.0$, 3.0, 4.0, 5.0, 9.0, $14.0 \times 10^{-5}(0,3.0,4.0,5.0,7.0,9.0,11.0,12.0 \times$ $\left.10^{-5}\right) \mathrm{M}$, respectively
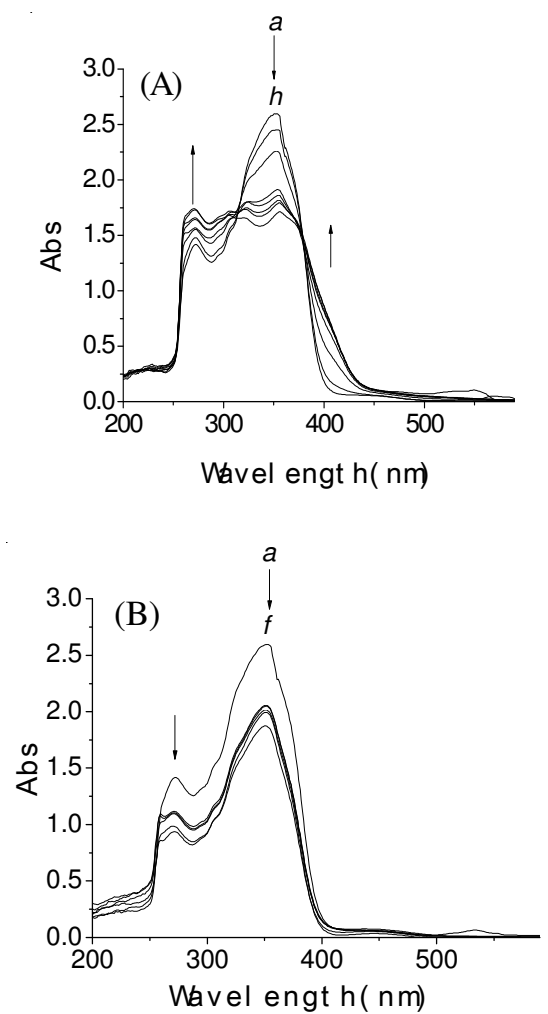

Fig. 2. UV-visible spectrophotometric titration of PSAP with (A) $\mathrm{Cu}^{2+}(\mathrm{B})$ $\mathrm{Fe}^{2+}$. The concentrations of $\mathrm{Cu}^{2+}\left(\mathrm{Fe}^{2+}\right) \mathrm{a} \rightarrow \mathrm{h}(\mathrm{a} \rightarrow \mathrm{f})$ were: $0,1.0,3.0$, 5.0, 6.0, 7.0, 8.0, $10.0 \times 10^{-5}\left(0,6.0,7.0,8.0,9.0,14.0 \times 10^{-5}\right) \mathrm{M}$, respectively

where $\left(1 / \mathrm{K}_{\mathrm{a}} \Delta \mathrm{A}\right)$ was the slope obtained from the BenesiHildebrand graph and $(1 / \Delta \mathrm{A})$ was the $y$-intercept. The binding 

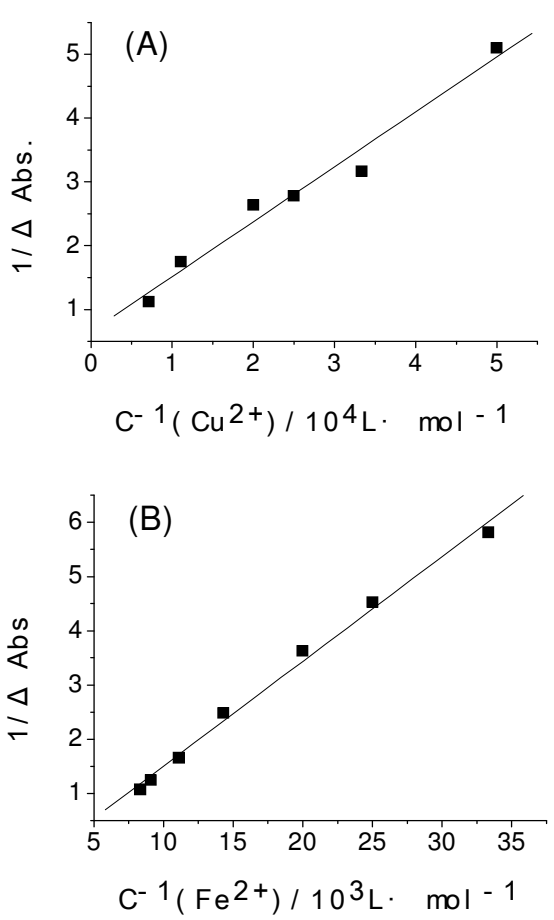

Fig. 3. Benesi-Hildebrand plots for the titration of OSAP with (A) $\mathrm{Cu}^{2+}$ and $\mathrm{Fe}^{2+}(\mathrm{B})$

constants of OSAP and PSAP using the above procedure were assessed. It was found that the binding constants of OSAP with $\mathrm{Cu}^{2+} / \mathrm{Fe}^{2+}$ were $7.58 \times 10^{3}$ and $2.22 \times 10^{3} \mathrm{M}^{-1}$ while that of PSAP were $6.20 \times 10^{3}$ and $2.10 \times 10^{4} \mathrm{M}^{-1}$, respectively, indicating that both OSAP and PSAP could efficiently chelate transition metal ions $\left(\mathrm{Cu}^{2+} / \mathrm{Fe}^{2+}\right)$ and transition metal ions chelation should be responsible for the antioxidant behaviour of OSAP and PSAP as they have significant metal ion binding constants.

Fluorescence studies on the interactions between OSAP/ PSAP and $\mathrm{Cu}^{2+} / \mathrm{Fe}^{2+}$ The fluorescence-quenching spectroscopy was also employed to study their chelation abilities with transition metal ions. Upon respective addition of transition metal ions $\left(\mathrm{Cu}^{2+}\right.$ and $\left.\mathrm{Fe}^{2+}\right)$ into the solution of OSAP and PSAP, the fluorescence intensity decreased gradually as in Figs. 4 and 5 .

Fluorescence quenching was described by the SternVolmer eqn. $1^{11-13}$.

$$
\frac{\mathrm{F}_{0}}{\mathrm{~F}}=1+\mathrm{k}_{\mathrm{q}} \tau_{0} \mathrm{c}(\mathrm{Q})=1+\mathrm{K}_{\mathrm{SV}} \mathrm{c}(\mathrm{Q})
$$

where $\mathrm{F}_{0}$ and $\mathrm{F}$ were the steady-state fluorescence intensities in the absence and presence of quencher (transition metal ions), respectively, $\mathrm{k}_{\mathrm{q}}$ the quenching rate constant of the biological molecule, $\mathrm{c}(\mathrm{Q})$ the concentration of quencher $\left(\mathrm{Cu}^{2+}\right.$ or $\left.\mathrm{Fe}^{2+}\right)$, $\tau_{0}$ the average lifetime of the molecule in the absence of quencher. $\mathrm{K}_{\mathrm{Sv}}$ was the Stern-Volmer quenching constant. Accordingly, eqn. 2 was applied to determine $\mathrm{K}_{\mathrm{Sv}}$ by linear regression of a plot of $\mathrm{F}_{0} / \mathrm{F}$ against $\mathrm{c}(\mathrm{Q})$ and the Stern-Volmer plots were shown in Fig. 6.

It was found that Stern-Volmer quenching constant $\mathrm{K}_{\mathrm{SV}}$ of OSAP with $\mathrm{Cu}^{2+} / \mathrm{Fe}^{2+}$ were $6.07 \times 10^{4}$ and $6.70 \times 10^{4} \mathrm{M}^{-1}$ while that of PSAP were $8.45 \times 10^{4}$ and $1.43 \times 10^{5} \mathrm{M}^{-1}$, respectively. The Stern-Volmer quenching constant data
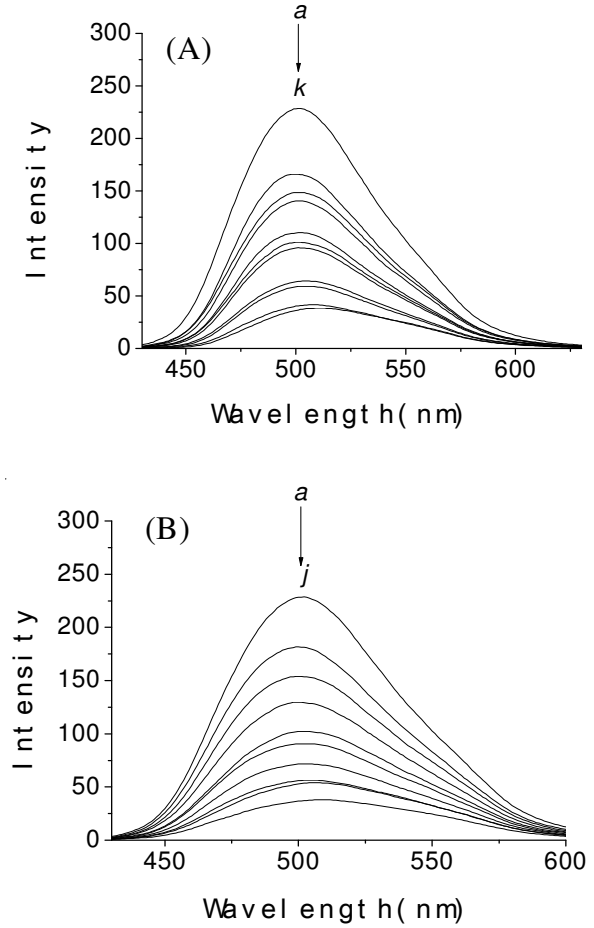

Fig. 4. Emission spectra of OSAP in the presence of various concentrations of transition metal ion $\mathrm{Cu}^{2+}(\mathrm{A})$ and $\mathrm{Fe}^{2+}(\mathrm{B})$. The concentrations of $\mathrm{Cu}^{2+}\left(\mathrm{Fe}^{2+}\right) \mathrm{a} \rightarrow \mathrm{k}(\mathrm{a} \rightarrow \mathrm{j})$ were: $0,2.5,3.0,4.0,4.5,5.0,6.0,7.0,8.0$, $9.0,10.0 \times 10^{-5}\left(0,3.0,4.0,5.0,5.5,6.0,7.0,8.0,9.0,10.0 \times 10^{-5}\right)$ $\mathrm{mol} \cdot \mathrm{L}^{-1}$, respectively
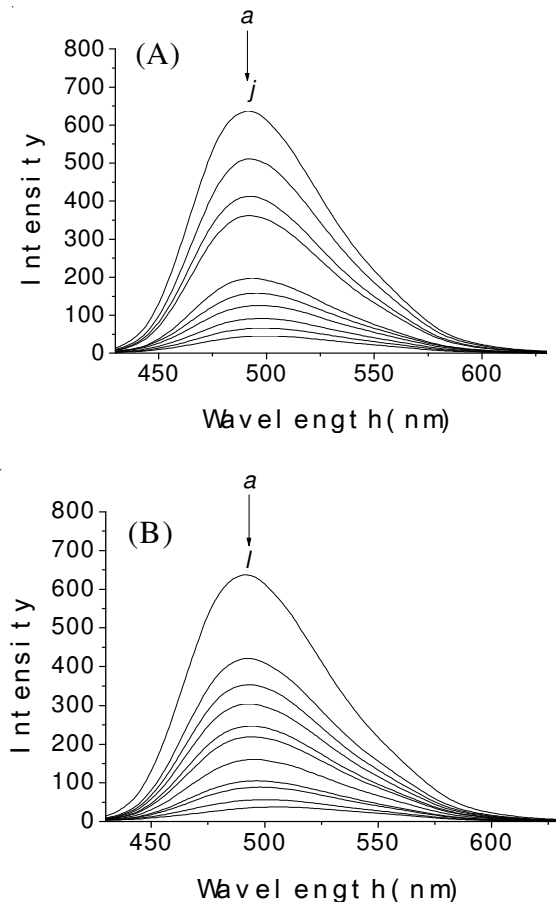

Fig. 5. Emission spectra of PSAP in the presence of various concentrations of transition metal ion $\mathrm{Cu}^{2+}(\mathrm{A})$ and $\mathrm{Fe}^{2+}(\mathrm{B})$. The concentrations of $\mathrm{Cu}^{2+}\left(\mathrm{Fe}^{2+}\right) \mathrm{a} \rightarrow \mathrm{j}(\mathrm{a} \rightarrow \mathrm{l})$ were: $0,4.0,6.0,7.0,10.0,11.0,12.0,13.0$, $14.0,15.0 \times 10^{-5}(0,4.0,5.0,6.0,7.0,8.0,9.0,10.0,11.0,12.0$, $\left.13.0,15.0 \times 10^{-5}\right) \mathrm{mol} \cdot \mathrm{L}^{-1}$, respectively

suggested that there were relatively sensitive binding between OSAP/PSAP and $\mathrm{Fe}^{2+} / \mathrm{Cu}^{2+}$, respectively, implying that OSAP and PSAP have significant chelation abilities with transition metal ions. 

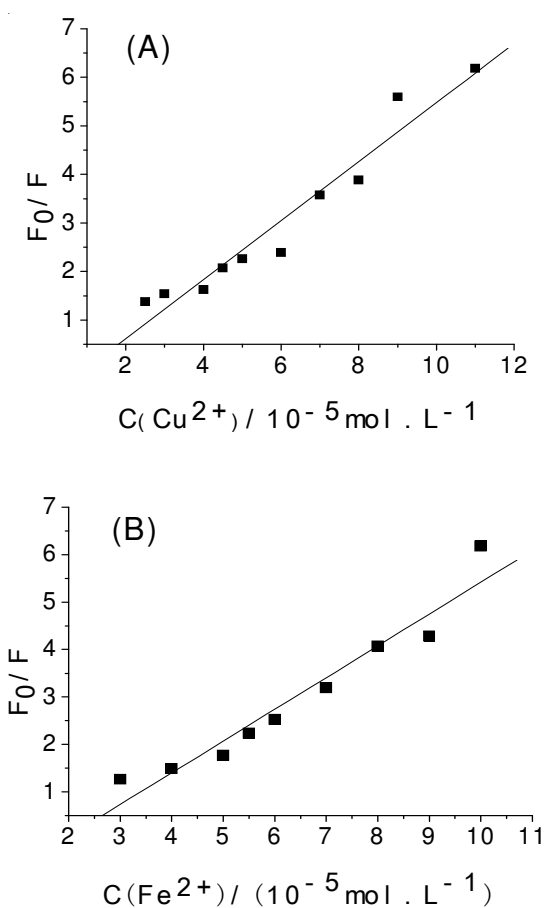

Fig. 6. Stern-Volmer plots for the quenching of OSAP by transition metal ion $\mathrm{Cu}^{2+}(\mathrm{A})$ and $\mathrm{Fe}^{2+}(\mathrm{B})$

Mass studies on the complexation between PSAP and OSAP with $\mathrm{Fe}^{2+}$ : Further studies on the transition metal ions chelation of OSAP and PSAP were carried out through respective complexation of PSAP with ferrous ion that assessed by mass spectrometer (Fig. 7), since that both the binding constant and Stern-Volmer quenching constant of PSAP with $\mathrm{Fe}^{2+}$ were the best. A 8:2 (v:v) mixture of methanol-water was used as the solvent. For comparison, the complexation of OSAP with $\mathrm{Fe}^{2+}$ was also determined by the mass spectra (Fig. 8).
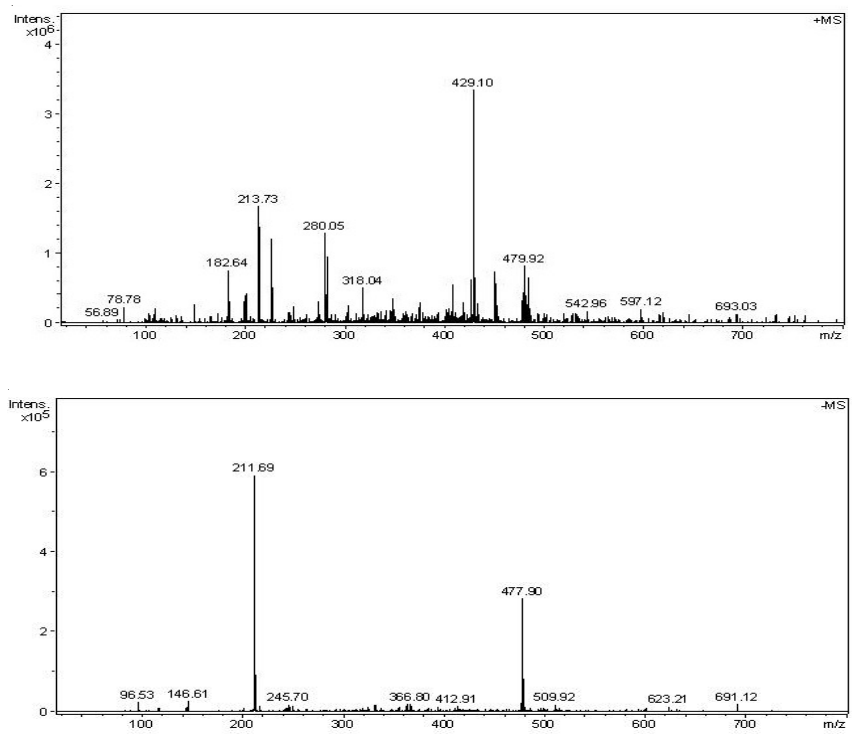

Fig. 7. Mass spectra of $30 \mu \mathrm{M}$ PSAP with $10 \mu \mathrm{M} \mathrm{Fe}^{2+}$ in a mixture of $8: 2$ (v:v) methanol : water
Mass spectra of these species corresponding to the formation of a 2:1 complex between PSAP (or OSAP) and ferrous ion was observed in each case: a PSAP-Fe ${ }^{2+}$ complex $\left(\mathrm{m} / \mathrm{z}=480\right.$, [PSAP-Fe(II)-(PSAP-H) ] ${ }^{+}$, Fig. 7) when PSAP was used and a OSAP-Fe ${ }^{2+}$ complex (m/z = 480, [OSAP-Fe(II)$(\mathrm{OSAP}-\mathrm{H})]^{+}$when OSAP was used. A close look at both the +MS and -MS patterns of the PSAP-Fe and OSAP-Fe complex (Fig. 7) suggested that they fit well the above results. This observation confirmed that PSAP and OSAP had good transition metal ions chelation abilities and could quickly and effectively form chelate complex with transition metal ions.

\section{Conclusion}

The transition metal ion chelation ability of OSAP and PSAP had been confirmed by UV-visible, fluorescencequenching spectroscopy and MS-spectra. The binding constants, Stern-Volmer quenching constants, as well as complexation assessed by mass spectra implicated that the superior antioxidant properties of OSAP and PSAP may be ascribed to the transition metal ions chelation mechanism.

\section{ACKNOWLEDGEMENTS}

This study was supported by the Fund of Guangxi Key Laboratory of Functional Phytochemicals Research and Utilization (No. FPRU2011-6), the Guilin Scientific Research and Technological Development Project (No. 20110106-2, 20120108-6) and the Guangxi Department of Education Research Projects (No. 200807MS075, 200807MS076, 200911MS281, 200911MS282).

\section{REFERENCES}

1. Y. Liu, G. Xu and L.M. Sayre, Chem. Res. Toxicol., 16, 1589 (2003).

2. Z. Liu, P.E. Minkler and L.M. Sayre, Chem. Res. Toxicol., 16, 901 (2003).

3. J.E. Brown, H. Khodr, R.C. Hider and C.A. Rice-Evans, Biochem. J., 330, 1173 (1998).

4. S.A.B.E. Van Acker, D.J. Van den Berg, M.N.J.L. Tromp, D.H. Griffioen, W.P. Van Bennekom, W.J.F. Van der Vijgh and A. Bast, Free Radic. Biol. Med., 20, 331 (1996).

5. R. Nino, C. Sandro and T.J. Marirosa, J. Agric. Food Chem., 54, 6343 (2006).

6. A. Amorati, F. Ferroni, G.F. Pedulli and L.Valgimigli, J. Org. Chem., 68, 9654 (2003).

7. R. Amorati, M. Lucarini, V. Mugnaini and G.F. Pedulli, J. Org. Chem., 69, 7101 (2004).

8. Y.Z. Tang and Z.Q. Liu, Cell Biochem. Funct., 25, 149 (2007).

9. Y.Z. Tang and Z.Q. Liu, Cell Biochem. Funct., 25, 701 (2007).

10. J.R. Lakowicz, Principles of Fluorescence Spectroscopy, Plenum Press, New York, p. 698 (1999).

11. M.R. Eftink, In ed.: T.G. Dewey, Biophysical and Biochemical Aspects of Fluorescence Spectroscopy, Plenum Press, New York, pp. 1-44 (1991).

12. A. Papadopoulou, R.J. Green and R.A. Frazier, J. Agric. Food Chem., 53, 158 (2005).

13. S.S. Lehrer, Biochemistry, 10, 3254 (1971). 